\title{
VH1-44 gene usage defines a subset of canine B-cell lymphomas associated with better patient survival
}

\author{
Hsiao-Wei Chen ${ }^{1,2,3}$, George W Small ${ }^{2,3}$, Alison Motsinger-Reif ${ }^{1,4}$, Steven E. Suter ${ }^{1,2,5}$, and \\ Kristy L. Richards $\mathbf{s}^{1,2,3}$ \\ ${ }^{1}$ Center for Comparative Medicine and Translational Research, North Carolina State University, \\ Raleigh, NC \\ ${ }^{2}$ Lineberger Comprehensive Cancer Center, Chapel Hill, NC \\ ${ }^{3}$ Division of Hematology/Oncology, University of North Carolina at Chapel Hill, NC \\ ${ }^{4}$ Bioinformatics Research Center, Department of Statistics, North Carolina State University, \\ Raleigh, NC \\ ${ }^{5}$ Department of Clinical Sciences, College of Veterinary Medicine, North Carolina State \\ University, Raleigh, NC
}

\begin{abstract}
The use of specific immunoglobulin heavy chain variable region $(\mathrm{VH})$ genes has been associated with increased patient survival in human B-cell lymphomas (hBCL). Given the similarity of human and canine BCL (cBCL) in morphology and clinical treatment, we examined the choice of $\mathrm{VH}$ in $\mathrm{cBCL}$ and determined whether $\mathrm{VH}$ gene selection was a distinct feature associated with survival time in dogs. VH gene selection and mutational status in $52 \mathrm{cBCL}$, including 29 diffuse large B-cell lymphomas (cDLBCL, the most common subtype of cBCL), were analyzed by comparison with the 80 published canine germline $\mathrm{VH}$ gene sequences. We further examined the prognostic impact of the subgroups defined by these features on canine survival. We found that VH1-44 was preferentially expressed in the majority of the 52 cBCLs (60\%) as well as in the majority of the cDLBCL subset (59\%). VH1-44 gene expression was associated with a statistically better overall survival ( $\mathrm{p}=0.039$ ) in cBCL patients, as well as in the cDLBCL subset of patients $(\mathrm{p}=0.038)$. These findings suggest that $\mathrm{VH}$ gene selection in $\mathrm{cBCL}$ is not random and may therefore have functional implications for cBCL lymphomagenesis, in addition to being a useful prognostic biomarker.
\end{abstract}

\section{Keywords}

immunoglobulin heavy chain variable region (VH); B-cell lymphoma; diffuse large B-cell lymphoma; survival; VH1-44

\footnotetext{
(C) 2013 Elsevier B.V. All rights reserved.
}

Richards and Suter co-corresponding authors: Kristy L. Richards, 1062 Genetic Medicine Bldg., Chapel Hill, NC 27599-7361, (919) 966-0374, kristy_richards@med.unc.edu, Steven E. Suter, 1051 William Moore Dr., Research \#308, Raleigh, NC 27607, (919) 513-0813, steven_suter@ncsu.edu.

Publisher's Disclaimer: This is a PDF file of an unedited manuscript that has been accepted for publication. As a service to our customers we are providing this early version of the manuscript. The manuscript will undergo copyediting, typesetting, and review of the resulting proof before it is published in its final citable form. Please note that during the production process errors may be discovered which could affect the content, and all legal disclaimers that apply to the journal pertain. 


\section{Introduction}

Diffuse large B-cell lymphoma (DLBCL), which accounts for $\sim 50 \%$ and $\sim 73 \%$ of hBCL and cBCL (Ponce et al., 2010), respectively, is the most common type of mature B-cell lymphoma in both humans and dogs. Canine patients are an attractive animal model to study the etiology and clinical therapy of BCL because of their close phylogenetic relationship with humans and the occurrence of spontaneous tumors in these animals (Laura Marconato, 2012). The value of dogs as a reliable BCL/DLBCL model depends on the similarity of pathological mechanisms shared at the molecular level between human and canine patients, and these similarities are just beginning to be explored.

Mature BCL, which arises from B cells transformed at various developmental stages, maintains molecular features of the cell of origin, including unique $\mathrm{VH}$ gene rearrangement and often, constitutive NF- $\kappa B$ activation (Davis et al., 2001). Molecular analysis of VH genes in $\mathrm{hBCL}$ reveals valuable information about the stage of differentiation that the B cell has reached prior to malignant transformation and also about the preferential use of specific VH genes (Lossos et al., 2000a; Lossos et al., 2000b). For example, hDLBCL with and without ongoing mutations in $\mathrm{VH}$ genes are suggested to arise from one of two distinct cell types: germinal center (GC) and post-GC lymphocytes, respectively (Lossos et al., 2000a).

The VH gene is formed by combinatorial permutations of different $\mathrm{V}, \mathrm{D}$, and $\mathrm{J}$ gene segments chosen from the $\mathrm{VH}$ gene repertoire and joined by addition or deletion of short coding sequences at the VD and DJ joints to increase diversity for positive antigen-driven selection (Das et al., 2008). VDJ recombination occurs prior to germinal center entry. VH gene usage is not random; biased $\mathrm{VH}$ gene usage has been reported in normal B-cell populations (Brezinschek et al., 1997), as well as in patients with several subtypes of hBCL, such as preferential VH3-21 use in mantle cell lymphoma (MCL) patients (Walsh et al., 2003) and overuse of VH4-34 in DLBCL patients (Davis et al., 2001; Gaurnier-Hausser et al., 2011; Hsu and Levy, 1995). MCL patients with lymphomas using VH3-21 also have longer survival times than those using other VH genes (Walsh et al., 2003). This biased usage of certain $\mathrm{VH}$ genes in hBCL can reflect selective pressures that occur before and/or after malignant transformation.

The canine $\mathrm{VH}$ gene repertoire includes $80 \mathrm{VH}, 6 \mathrm{DH}$, and $3 \mathrm{JH}$ segments (Bao et al., 2010; Das et al., 2008). VH1-62 (27.0\%) and VH1-44 (23.4\%) were the most frequently used VH gene clone sequences in splenic B cells (Bao et al., 2010). All other VH genes were used with less than $11.7 \%$ frequency. Based on sequence homology, canine $\mathrm{VH}$ genes are divided into $3 \mathrm{VH}$ families (VH1, VH2, and $\mathrm{VH} 3$ ) each sharing at least 70\% homology among family members. The vast majority of $\mathrm{VH}$ genes (76) belong to the $\mathrm{VH} 1$ family while VH2-51, VH2-64, and VH2-66 belong to the VH2 family. VH3-80 is the only VH3 family member. Compared to the seven human VH gene families by sequence similarity, the canine VH1 family is similar to the human VH3 family, which is also the largest family; and the canine $\mathrm{VH} 2$ and $\mathrm{VH} 3$ are most similar to the human $\mathrm{VH} 1$ and $\mathrm{VH} 4$ families, respectively.

Our previous analysis of VH gene mutation status in cBCL has demonstrated the presence of two subgroups - one with and another without ongoing somatic mutations, comparable to hDLBCL (Richards et al., 2013). Here, we further investigated VH gene usage in cBCL and its potential prognostic impact. Since molecular differences between cBCL histologic subtypes have not been fully identified, we also analyzed the DLBCL subgroup separately, to determine if their properties were similar to $\mathrm{CBCL}$ as a whole. Our findings elucidate similarities in the usage of $\mathrm{VH}$ genes between $\mathrm{hBCL}$ and $\mathrm{CBCL}$, with a particular focus on DLBCL and effects of $\mathrm{VH}$ gene usage on canine patient survival. This molecular analysis highlights the genetic similarity between human and canine lymphomagenesis, promoting 
the value of the canine model in clinical trials, drug development, and molecular analysis of hBCL.

\section{Materials and methods}

\subsection{Canine samples}

Patient samples were collected by lymph node biopsies obtained from canine patients, with owner consent, presenting with clinical signs and hematologic abnormalities consistent with BCL/DLBCL to the Veterinary Health Complex at the North Carolina State College of Veterinary Medicine (NCSU-VHC). The protocol was approved by the Institutional Animal Care and Use Committee of North Carolina State University. A diagnosis was made based on a morphological evaluation of immunohistochemistry and/or flow cytometry using CD79a, CD3 (AbD Serotec, Raleigh, NC), and PAX5 (Leica Microsystems, Wetzlar, Germany) antibodies, which cross-reacted appropriately in positive and negative control canine tissues. CD79a was a marker for B-cell lymphomas; CD3, for T-cell lymphomas; and PAX5, for pre-B and B-cell lymphomas. A sample was considered positive if over 30\% of the tumor cells were stained with antibodies. Twenty-nine samples had excisional biopsies with lymph node effacement with diffuse sheets of large B cells by hematoxylin and eosin (H\&E) staining and were morphologically characterized as cDLBCL. A more detailed description of samples has been described previously (Richards et al., 2013).

\subsection{PCR amplification and subclone sequencing}

A total of 52 BCL canine patients, including 29 DLBCLs, were sequenced and analyzed for VH gene usage by subcloning of the PCR products. Lymphoma tissue from each sample was isolated and frozen in Trizol (Invitrogen, Carlsbad, CA) at $-80^{\circ} \mathrm{C}$ until extraction. RNA extraction was performed per manufacturer's protocol and then purified over an RNeasy column (Qiagen, Valencia, CA). For each sample, $1 \mu \mathrm{g}$ of RNA was reverse transcribed to cDNA using an oligo-d(T) primer and a first-strand cDNA synthesis kit (Roche, Indianapolis, IN) and used as a template for conventional PCR. Primers were designed to amplify a 432-base-pair region starting from the start of the IGHV open reading frame to the JH section (forward primer sequence: 5'-CCATGGAGTCTGTGCTCTGC-3'; reverse primer sequence : 5'-CTGAGGAGACGGTGACCAGG-3'). The PCR product was confirmed by agarose gel electrophoresis with ethidium bromide staining. In this study, primers were designed to amplify only VH genes in the canine VH1 family ( 76 of 80 genes are in the VH1 family), and these primers successfully amplified 52/53 canine lymphoma samples. PCR products were then cloned into plasmid DNA vectors and transformed into E.coli using Zero Blunt TOPO PCR cloning kit (Invitrogen, Carlsbad, CA) or the TOPO II cloning kit (Invitrogen, Carlsbad, CA). For each sample, 8 to 27 colonies containing plasmids with the appropriate sized insert were selected for sequencing at the University of North Carolina Genomic Analysis Core Facility (Chapel Hill, NC) (Supplementary S1).

\subsection{Analysis of VH gene sequences}

ViroBLAST (Deng et al., 2007) was used to identify the germline VH gene present in patient samples by BLASTing the clone sequences against the 80 germline VH genes in the canine VH repertoire (Bao et al., 2010). Each individual clone was assigned to the closest germline VH gene by sequence similarity. For each sample, the most frequently used $\mathrm{VH}$ gene segment was then considered as the germline $\mathrm{VH}$ gene used in the cell of origin, and the degree of homology was defined by the average percentage identity for all the clones compared to the designated germline $\mathrm{VH}$ gene. If the homology of a case was less than $98 \%$ compared with the germline, the VH gene was defined as mutated (Walsh and Rosenquist, 2005). 


\subsection{Statistical analysis}

In order to evaluate the prognostic impact of VH gene usage on the overall survival (OS) and progression-free survival (PFS) of canine BCL/DLBCL patients, the Kaplan-Meier method was used to estimate survival distribution, and the survival curves were examined by the $\log$-rank test. $P$-values $\leq 0.05$ were considered to be significant. Statistical calculations were performed using $\mathrm{R}$, version 2.12.1.

\section{Results}

\subsection{Mutational status and VH gene usage in canine BCL/DLBCL}

Of the $52 \mathrm{cBCL}$ cases, the similarity averages were all $<98 \%$ compared to the germline $\mathrm{VH}$ sequences, suggesting that all had become mutated via somatic hypermutation (SHM). Somatic hypermutation in VH genes is a hallmark of germinal center (GC) entry, so we inferred that these lymphomas were derived from either GC or post-GC stages.

There were eight VH genes identified in the $52 \mathrm{cBCL}$ cases, VH1-44( $\mathrm{n}=31), \mathrm{VH1}-62(\mathrm{n}=5)$, VH1-77(n=5), VH1-41(n=4), VH1-47(n=3), VH1-79(n=2), VH1-48(n=1), and VH1-35(n=1) (Table 1). The average similarity of the eight germline VH genes identified ranged from $89.0 \%$ to $93.4 \%$. The frequency of VH1-44 usage (59.6\%) was six times higher than that of the next most frequently used VH genes, VH1-62 (9.6\%) and VH1-77 (9.6\%).

We observed a noticeable bias in the use of the VH1-44 gene among the 52 cases (31/52), so we compared this proportion to the number of VH1-44 clones identified in B-cells from three normal dogs (26/111 clones) (Bao et al., 2010), and found a significant difference ( $\mathrm{p}<$. 0002, chi-square test). We analyzed a subset of the cBCLs based on histological classification (Richards et al., 2013), examining the cDLBCL subset separately to determine if the results were similar. VH1-44 was also the most frequently used VH gene found in the cDLBCL subset, used in 17 out of 29 cases (58.6\%). This frequency was also much higher than the second and third most frequently used genes, VH1-77 (13.8\%) and VH1-41 $(10.3 \%)$.

\subsection{Comparison of VH gene usage in dogs and humans}

Since canine VH1-44 was the most commonly used VH gene in cBCL/DLBCL and also frequently found in normal cells, we examined the distribution of $\mathrm{VH}$ gene usage in human patients and normal B-cell populations from published studies in order to determine whether its ortholog was also being predominantly used in humans. The most frequently used $\mathrm{VH}$ genes in human DLBCL were VH4-34 (8.6-28.3\%) and VH3-23 (10.3-15\%) (Table 1) (Lossos et al., 2000b; Ruminy et al., 2011), and the most frequent VH gene in human normal B-cell populations was VH3-23 (>11\%) (Brezinschek et al., 1997). Based on sequence homology, the canine VH1 family corresponds to the human VH3 family, and the VH genes of most cBCL cases in this study belonged to this family, with human VH3-23 having the highest homology (89\% identical) with canine VH1-44. Although it is difficult to identify the specific human $\mathrm{VH}$ gene that is derived from the same ancestral gene as canine VH1-44, canine VH1-44 is most likely orthologous to human VH3-23, VH3-33, VH3-21, and VH3NL1 based on sequence similarity (Table 2). Interestingly, since the VH3-23 gene is commonly used in human normal and lymphoma B cells, this VH gene family in both humans and dogs may share the same function in both normal B-cell development and lymphomagenesis.

The orthologs of the human VH4 family, including VH4-34, were rarely found in the canine $\mathrm{VH}$ gene repertoire. The canine $\mathrm{VH}$ gene most homologous to the human $\mathrm{VH} 4$ family was VH3-80, with a similarity between canine VH3-80 and human VH4-34 of only 77\%. 


\subsection{Association between VH1-44 usage and canine survival}

To determine the prognostic impact of VH1-44 gene usage on canine survival, we divided canine patients into a VH1-44 group and a non-VH1-44 group for both BCL and DLBCL datasets, and determined whether there was a statistically significant survival difference between the two groups. For both BCL and DLBCL, the canine patients with lymphomas derived from cells expressing VH1-44 had a significantly longer OS than those not expressing VH1-44 (Table 3 and Figure 1). For the 52 BCLs, median OS for the VH1-44 group was 505 days, which was 2.4 fold higher than the non-VH1-44 group (215 days, $\mathrm{p}=0.039$ ). The hazard ratio (HR) was 0.514 , indicating that $48.6 \%$ lower incidence of death for the VH1-44 group compared with the non-VH1-44 group. Although the PFS for the VH1-44 group was 1.4 fold longer than the non-VH1-44 group, it was not statistically significant $(\mathrm{p}=0.175)$. Similar findings were also observed when analyzing the subset of 29 DLBCLs. The median OS for the VH1-44 group was 493 days, which was 2.7 fold higher than the non-VH1-44 group (182 days, $\mathrm{p}=0.038$ ). The HR was 0.405 , indicating that $59.5 \%$ lower incidence of death for the VH1-44 group compared with the non-VH1-44 group. The median PFS for the VH1-44 group was 210 days, which was 1.5 fold higher than the nonVH1-44 group, although this was not statistically significant $(\mathrm{p}=0.126)$ (Table 3 ).

\section{Discussion}

We found that the canine $\mathrm{VH}$ gene $\mathrm{VH1}-44$ was overrepresented in $\mathrm{cBCL}$ relative to normal B cells (Bao et al., 2010), and that the use of the VH1-44 gene in cBCL was associated with better OS, but not PFS. Results were similar, both in VH1-44 frequency and survival analysis, whether all $\mathrm{cBCL}$ or just the subset of known $\mathrm{cDLBCL}$ were analyzed, indicating similar effects of $\mathrm{VH}$ gene usage across $\mathrm{cBCL}$ subtypes.

Bias in $\mathrm{VH}$ gene usage in humans has been associated with many diseases and disease outcomes. For instance, the use of specific VH genes has been associated with autoimmunity (Deckmyn et al., 1994; Elagib et al., 1999; Fang et al., 1994; Roark et al., 2002; Silberstein et al., 1991; Stevenson et al., 1993). In hairy cell leukemia (HCL), lymphocytes expressing VH4-34 were less susceptible to checkpoints for clonal deletion, resulting in a poorer prognosis (Arons and Kreitman, 2011; Arons et al., 2009). In MCL, the use of human VH3-21 was reported to influence the use of a specific $\lambda$ light chain, $\mathrm{V}_{\lambda} 3-19$, and patients with this combination had a better survival (Walsh et al., 2003). A bias in VH gene usage has been found in $\mathrm{hDLBCL}$, but $\mathrm{VH}$ gene usage was not associated with patient survival (Lossos et al., 2000b). Presumably, these biases exist, both in humans and in our study of cBCL, because certain $\mathrm{VH}$ genes provide a survival advantage to cells during lymphomagenesis. We speculate that VH1-44 could lead to improved overall survival in patients due to differential B-cell receptor/apoptosis signaling, resulting in increased susceptibility to chemotherapeutic agents and/or less aggressive lymphoma growth.

This study has several limitations that should be considered when interpreting our results. First, the dogs used in our study were not uniformly treated with the same chemotherapeutic regimen. Second, canine overall survival time is impacted by other factors such as owner preferences rather than disease biology alone. Third, the canine VH repertoire has not been comprehensively studied. The numeration of the canine $\mathrm{VH}$ repertoire is limited to only three normal dogs differing in breed from the ones used in this study. Therefore, differences in VH gene usage between normal and lymphoma cells may be biased by factors other than disease. Additional studies will be needed to corroborate our results. 


\section{Conclusion}

Expression of the VH1-44 gene predicts overall survival of cBCL and cDLBCL patients. A comparative analysis of canine VH1-44 and its human homolog, VH3-23, indicates that this biology may be evolutionarily conserved in hBCL. Our results identify a novel prognostic biomarker for differential survival in cBCL patients, and this could possibly extend to $\mathrm{hBCL}$. Our findings indicate that canine patients are a representative animal model for human BCL immunopathology.

\section{Supplementary Material}

Refer to Web version on PubMed Central for supplementary material.

\section{Acknowledgments}

We thank Tangi Smallwood for critical editing and David Bird for helpful discussions. This work was supported by a developmental grant from the North Carolina University Cancer Research Fund administered by the Lineberger Comprehensive Cancer Center to KLR, AMR, and SES. KLR is supported by a Mentored Research Scholar Grant in Applied and Clinical Research (MSRG-12-086-01-TBG) from the American Cancer Society.

\section{References}

Arons E, Kreitman RJ. Molecular variant of hairy cell leukemia with poor prognosis. Leuk Lymphoma. 2011; 52(Suppl 2):99-102. [PubMed: 21599610]

Arons E, Suntum T, Stetler-Stevenson M, Kreitman RJ. VH4-34+ hairy cell leukemia, a new variant with poor prognosis despite standard therapy. Blood. 2009; 114:4687-4695. [PubMed: 19745070]

Bao Y, Guo Y, Xiao S, Zhao Z. Molecular characterization of the VH repertoire in Canis familiaris. Vet Immunol Immunopathol. 2010; 137:64-75. [PubMed: 20483487]

Brezinschek HP, Foster SJ, Brezinschek RI, Dorner T, Domiati-Saad R, Lipsky PE. Analysis of the human $\mathrm{VH}$ gene repertoire. Differential effects of selection and somatic hypermutation on human peripheral CD5(+)/IgM+ and CD5(-)/IgM+ B cells. J Clin Invest. 1997; 99:2488-2501. [PubMed: 9153293]

Das S, Nozawa M, Klein J, Nei M. Evolutionary dynamics of the immunoglobulin heavy chain variable region genes in vertebrates. Immunogenetics. 2008; 60:47-55. [PubMed: 18196235]

Davis RE, Brown KD, Siebenlist U, Staudt LM. Constitutive nuclear factor kappaB activity is required for survival of activated B cell-like diffuse large B cell lymphoma cells. J Exp Med. 2001; 194:1861-1874. [PubMed: 11748286]

Deckmyn H, Zhang J, Van Houtte E, Vermylen J. Production and nucleotide sequence of an inhibitory human IgM autoantibody directed against platelet glycoprotein Ia/IIa. Blood. 1994; 84:1968-1974. [PubMed: 7545950]

Deng W, Nickle DC, Learn GH, Maust B, Mullins JI. ViroBLAST: a stand-alone BLAST web server for flexible queries of multiple databases and user's datasets. Bioinformatics. 2007; 23:2334-2336. [PubMed: 17586542]

Elagib KE, Tengner P, Levi M, Jonsson R, Thompson KM, Natvig JB, Wahren-Herlenius M. Immunoglobulin variable genes and epitope recognition of human monoclonal anti-Ro 52-kd in primary Sjogren's syndrome. Arthritis and rheumatism. 1999; 42:2471-2481. [PubMed: 10555043]

Fang Q, Kannapell CC, Gaskin F, Solomon A, Koopman WJ, Fu SM. Human rheumatoid factors with restrictive specificity for rabbit immunoglobulin G: auto- and multi-reactivity, diverse VH gene segment usage and preferential usage of V lambda IIIb. The Journal of experimental medicine. 1994; 179:1445-1456. [PubMed: 7545920]

Gaurnier-Hausser A, Patel R, Baldwin AS, May MJ, Mason NJ. NEMO-binding domain peptide inhibits constitutive NF-kappaB activity and reduces tumor burden in a canine model of relapsed, refractory diffuse large B-cell lymphoma. Clin Cancer Res. 2011; 17:4661-4671. [PubMed: 21610150] 
Hsu FJ, Levy R. Preferential use of the VH4 Ig gene family by diffuse large-cell lymphoma. Blood. 1995; 86:3072-3082. [PubMed: 7579401]

Laura Marconato, MEG.a.S.C. The dog as a possible animal model for human non-Hodgkin lymphoma: a review. Hematol Oncol. 2012

Lossos IS, Alizadeh AA, Eisen MB, Chan WC, Brown PO, Botstein D, Staudt LM, Levy R. Ongoing immunoglobulin somatic mutation in germinal center B cell-like but not in activated B cell-like diffuse large cell lymphomas. Proc Natl Acad Sci U S A. 2000a; 97:10209-10213. [PubMed: 10954754]

Lossos IS, Okada CY, Tibshirani R, Warnke R, Vose JM, Greiner TC, Levy R. Molecular analysis of immunoglobulin genes in diffuse large B-cell lymphomas. Blood. 2000b; 95:1797-1803. [PubMed: 10688840]

Ponce F, Marchal T, Magnol JP, Turinelli V, Ledieu D, Bonnefont C, Pastor M, Delignette ML, Fournel-Fleury C. A morphological study of 608 cases of canine malignant lymphoma in France with a focus on comparative similarities between canine and human lymphoma morphology. Vet Pathol. 2010; 47:414-433. [PubMed: 20472804]

Richards KL, Motsinger-Reif AA, Chen HW, Fedoriw Y, Fan C, Nielsen DM, Small GW, Thomas R, Smith C, Dave SS, Perou CM, Breen M, Borst LB, Suter SE. Gene profiling of canine B-cell lymphoma reveals germinal center and post-germinal center subtypes with different survival times, modeling human DLBCL. Cancer Res. 2013; 73:5029-5039. [PubMed: 23783577]

Roark JH, Bussel JB, Cines DB, Siegel DL. Genetic analysis of autoantibodies in idiopathic thrombocytopenic purpura reveals evidence of clonal expansion and somatic mutation. Blood. 2002; 100:1388-1398. [PubMed: 12149222]

Ruminy P, Etancelin P, Couronne L, Parmentier F, Rainville V, Mareschal S, Bohers E, Burgot C, Cornic M, Bertrand P, Lenormand B, Picquenot JM, Jardin F, Tilly H, Bastard C. The isotype of the BCR as a surrogate for the GCB and ABC molecular subtypes in diffuse large B-cell lymphoma. Leukemia. 2011; 25:681-688. [PubMed: 21233831]

Silberstein LE, Jefferies LC, Goldman J, Friedman D, Moore JS, Nowell PC, Roelcke D, Pruzanski W, Roudier J, Silverman GJ. Variable region gene analysis of pathologic human autoantibodies to the related $\mathrm{i}$ and I red blood cell antigens. Blood. 1991; 78:2372-2386. [PubMed: 1657249]

Stevenson FK, Longhurst C, Chapman CJ, Ehrenstein M, Spellerberg MB, Hamblin TJ, Ravirajan CT, Latchman D, Isenberg D. Utilization of the VH4-21 gene segment by anti-DNA antibodies from patients with systemic lupus erythematosus. Journal of autoimmunity. 1993; 6:809-825. [PubMed: 8155258]

Walsh SH, Rosenquist R. Immunoglobulin gene analysis of mature B-cell malignancies: reconsideration of cellular origin and potential antigen involvement in pathogenesis. Med Oncol. 2005; 22:327-341. [PubMed: 16260850]

Walsh SH, Thorselius M, Johnson A, Soderberg O, Jerkeman M, Bjorck E, Eriksson I, Thunberg U, Landgren O, Ehinger M, Lofvenberg E, Wallman K, Enblad G, Sander B, Porwit-MacDonald A, Dictor M, Olofsson T, Sundstrom C, Roos G, Rosenquist R. Mutated VH genes and preferential VH3-21 use define new subsets of mantle cell lymphoma. Blood. 2003; 101:4047-4054.

[PubMed: 12637326] 
(A) Grouping by VH1-44 usage (52 dogs, OS)

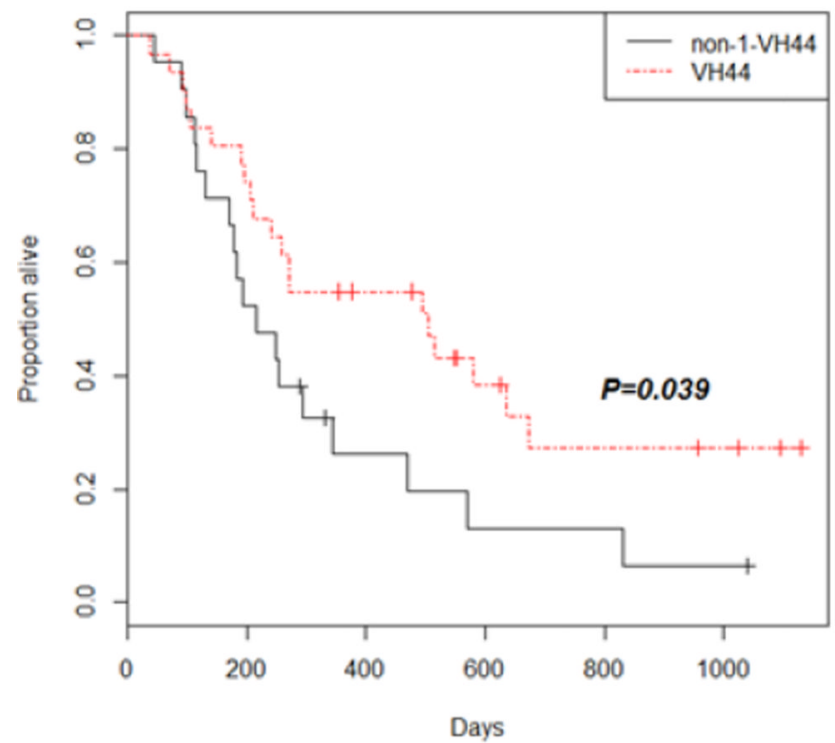

(C) Grouping by the VH1-44 usage (29 dogs, OS)

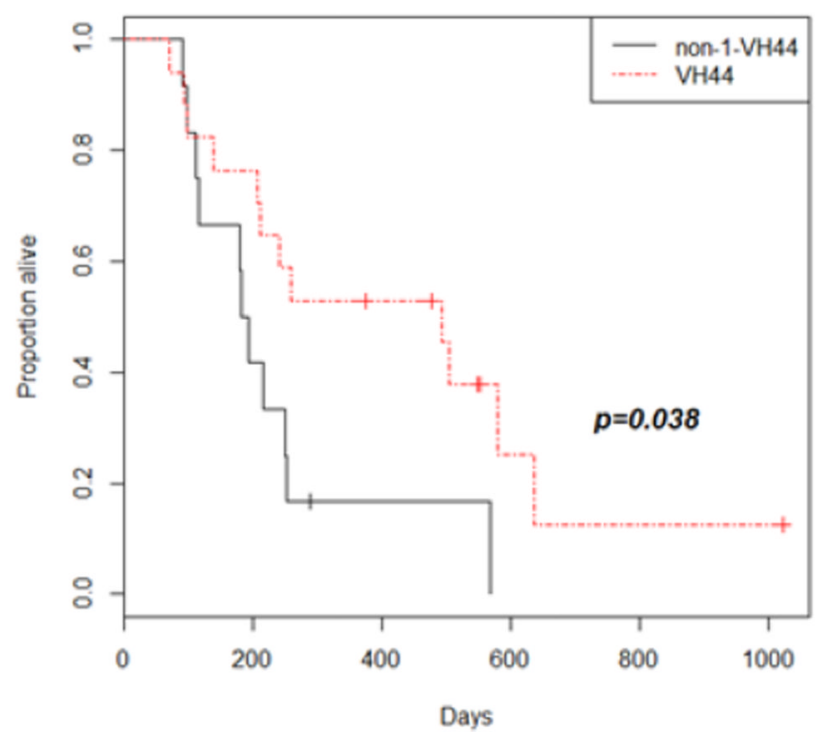

(B) Grouping by VH1-44 usage (52 dogs, PFS)

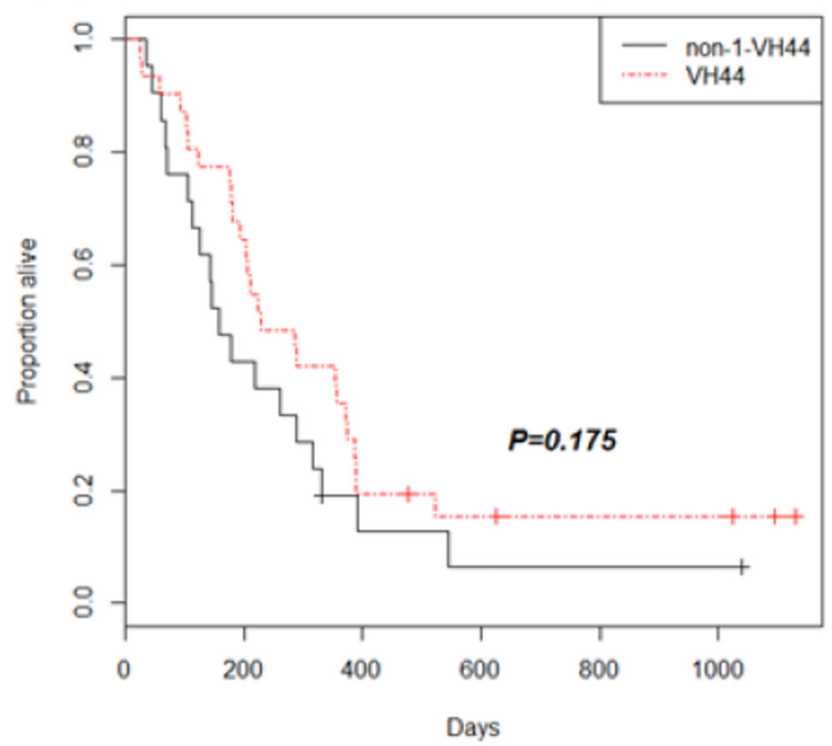

(D) Grouping by the VH1-44 usage (29 dogs, PFS)

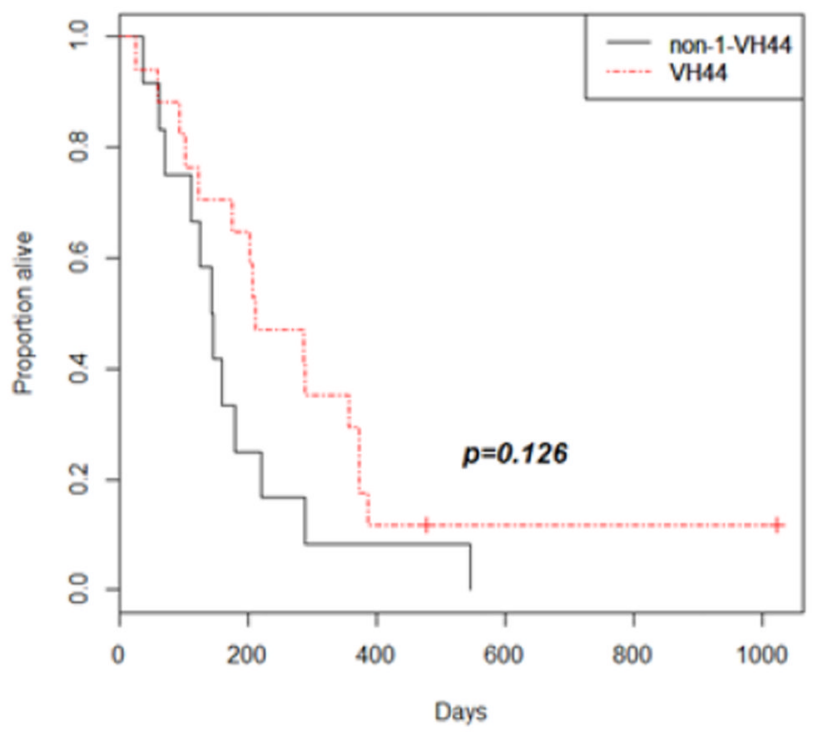

Figure 1.

Kaplan Meier curves of the (A) overall survival and (B) progression-free survival in cBCL patients with and without VH1-44 gene usage. Similarly, (C) overall survival and (D) progression-free survival in cDLBCL with and without VH1-44 gene usage. 


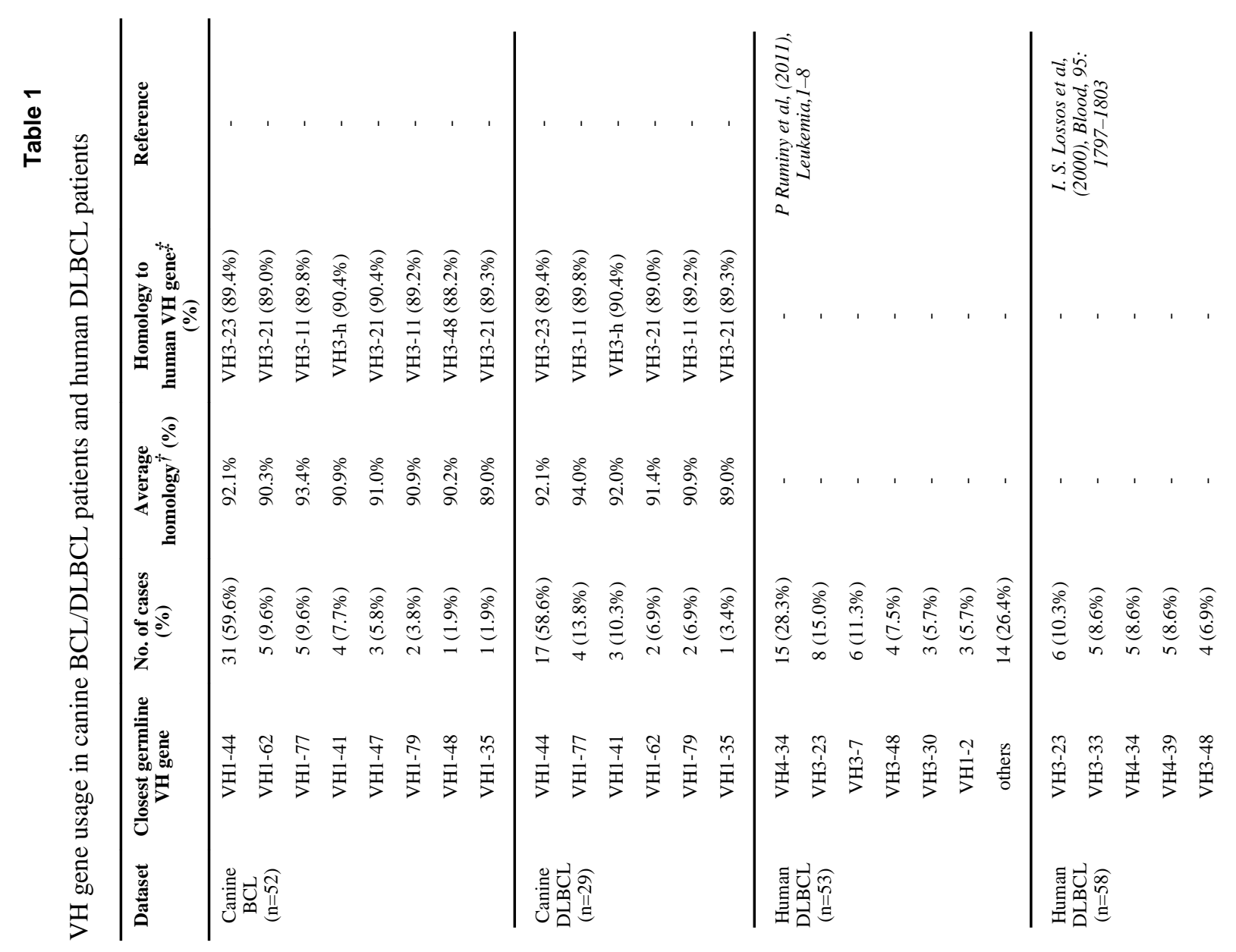

Vet Immunol Immunopathol. Author manuscript; available in PMC 2015 February 15. 


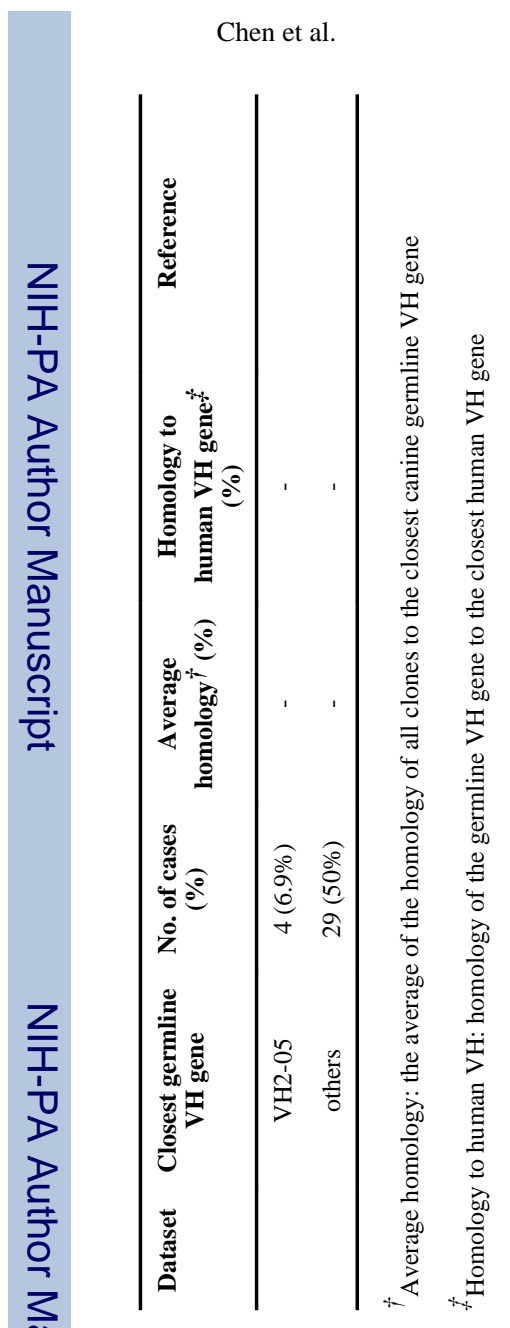

Page 10 
Table 2

List of human VH genes that are highly homologous to canine VH1-44

\begin{tabular}{cccc}
\hline Canine VH gene & Human VH gene $^{\boldsymbol{I}}$ & Homology $^{2}$ & Homology (\%) $^{\mathbf{3}}$ \\
\hline VH1-44 & VH3-23*04 & $262 / 293(295)$ & 89 \\
& VH3-23*03 & $262 / 293(295)$ & 89 \\
& VH3-33*03 & $261 / 292(295)$ & 89 \\
& VH3-23*05 & $261 / 293(295)$ & 89 \\
VH3-23*01 & $261 / 293(295)$ & 89 \\
& VH3-33*06 & $260 / 292(295)$ & 89 \\
& VH3-33*01 & $259 / 291(295)$ & 89 \\
& VH3-NL1*01 & $259 / 292(295)$ & 88 \\
& VH3-21*04 & $259 / 292(295)$ & 88 \\
& VH3-23*02 & $259 / 293(295)$ & 88 \\
\hline
\end{tabular}

\footnotetext{
${ }^{1}$ An asterisk and a two-figure number represent allele polymorphisms for each $\mathrm{VH}$ family gene. $* 01$ is the sequence selected as the reference sequence; $* 02, * 03$, etc. are other alleles with polymorphic sequence.

${ }^{2} \mathrm{H}$ parentheses

${ }^{3}$ Homology: the percentage of identical nucleotides
} 
